Cahiers $d u$ MONDE RUSSE

\section{Cahiers du monde russe}

Russie - Empire russe - Union soviétique et États indépendants

45/3-4 | 2004

Varia

\title{
Stéphane Mund, Orbis Russiarum
}

\section{Pierre GONNEAU}

\section{OpenEdition \\ Journals}

Édition électronique

URL : https://journals.openedition.org/monderusse/2683

DOI : $10.4000 /$ monderusse. 2683

ISSN : $1777-5388$

Éditeur

Éditions de l'EHESS

Édition imprimée

Date de publication : 1 juillet 2004

Pagination : 617-619

ISBN : 2-7132-2009-2

ISSN : $1252-6576$

Référence électronique

Pierre GONNEAU, «Stéphane Mund, Orbis Russiarum », Cahiers du monde russe [En ligne], 45/3-4 I 2004, mis en ligne le 25 novembre 2011, consulté le 03 septembre 2022. URL : http://

journals.openedition.org/monderusse/2683; DOI : https://doi.org/10.4000/monderusse.2683

Ce document a été généré automatiquement le 3 septembre 2022.

Tous droits réservés 


\title{
Stéphane Mund, Orbis Russiarum
}

\author{
Pierre GONNEAU
}

\section{RÉFÉRENCE}

Stéphane MUND, Orbis Russiarum. Genèse et développement de la représentation du monde « russe » en Occident à la Renaissance. Genève, Droz, 2003, 598 p. (Travaux d'humanisme et Renaissance, 382)

1 Stéphane Mund nous offre un excellent pendant français aux travaux de Marshall T. Poe ${ }^{1}$. Il commence par résumer l'état des connaissances médiévales des Slaves orientaux (p. 21-22, 41-42), tout en montrant que ces sources, fragmentaires et dispersées, n'ont pas exercé d'influence sur la vision moderne du monde « russe» (p. 420). Les travaux des géographes antiques sont davantage utilisés, de manière plus ou moins critique, par les auteurs du XVIe siècle. Toutefois, le règne du grand-prince de Moscou Ivan III (1462-1505) inaugure une période nouvelle où l'Occident découvre pour de bon la Russie qu'il perçoit à la fois comme une menace et comme un allié potentiel (p.22). Les deux motifs principaux d'espoir et de crainte sont la force militaire de l'État moscovite et l'adhésion des Slaves orientaux à l'orthodoxie. Les grandes puissances catholiques, comme la papauté, Venise, ou l'Empire romain germanique, espèrent enrôler les Russes dans le combat contre les Turcs (p. 191) et, qui sait, les amener à une union des Églises (p. 398). De leur côté, les pays frontaliers de la Russie, la Pologne-Lituanie et la Livonie, voient le danger d'invasion que présente pour eux un voisin en pleine ascension.

2 L'étude de Stéphane Mund est systématique, toujours appuyée sur des références précises à un très riche corpus d'ouvrages. L'auteur accorde toute l'attention requise à la carrière des voyageurs, auteurs et compilateurs, qui, malgré la diversité de leurs origines, sont presque tous des membres relativement connus de la république des lettres, des diplomates érudits ou des marchands qui ont tâté de l'université (p. 58, 181-182, 328-329). Ils évoluent dans un cercle restreint où les contacts personnels sont fréquents, où l'information circule vite et où les emprunts sont donc faciles. Les principaux centres de diffusion de leurs publications sont Bâle, Francfort et Venise et, dans une moindre 
mesure, Cracovie et Londres (p. 379). La Russie remporte plusieurs succès de librairie : en quelques années, les livres du diplomate impérial Sigismund von Herberstein, du Polonais Maciej de Miechów et de l'Italien Paolo Giovio connaissent plusieurs éditions dans des villes différentes (p. 380, 385-386). La langue reine, à la fois savante et élégante, est bien entendu le latin. Il est privilégié par les rédacteurs de traités chorographiques, de chroniques et de poèmes qui se posent en émules de leurs modèles antiques ou médiévaux, mais aussi par certains auteurs de récits de voyages, comme Herberstein (p. 97, 200, 332, 351-354). Le deuxième cercle de diffusion est celui de l'allemand et de l'italien, langues dans lesquelles sont composés certains ouvrages originaux et de nombreuses traductions (p. 96, 200, 340-348, 388); on peut aussi mentionner à ce niveau le polonais, car s'il y a peu de traductions en polonais, on compte une production intéressante de pamphlets anti-russes dans cette langue (p. 341-345). La troisième aire linguistique, celle de l'anglais, est à la fois riche en documents et fermée sur elle-même, car peu d'intellectuels européens lisent cette langue en-dehors des îles Britanniques (p. 96). Enfin, on constate que la France, les pays ibériques et scandinaves font figure de parents pauvres pour la production et surtout pour la traduction d'ouvrages concernant le monde russe (p. 44, 388). Le retard français, bien connu, reflète l'absence de relations commerciales et diplomatiques directes. Le cas des Scandinaves est plus étrange et mériterait d'être mieux comparé avec celui des Livoniens (germanophones) et des Polono-Lituaniens. Ivan le Terrible n'a visiblement pas aussi fortement impressionné Stockholm que Riga ou Vilna...

Malgré leur caractère toujours plus ou moins partisan et condescendant, les récits de voyage, les traités de chorographie et même les pamphlets dénonçant les exactions des Russes (en Livonie en particulier) donnent une image "globalement correcte» de la Russie (p. 164, 318, 349). Elle a le plus souvent une coloration négative parce que les auteurs ne reconnaissent pas chez les Russes les signes ostensibles de la culture et du goût classiques qu'ils considèrent comme la marque universelle de la civilisation (p. 118, 128-130). Il est facile d'assimiler les Russes «barbares » aux Scythes ou aux Sarmates Roxolanes (p.168, 336, 350, 454) des géographes antiques. Une comparaison, plus moderne, avec les Turcs, est esquissée par l'anglais Fletcher (p. 276), mais aussi dans certains pamphlets qui représentent Ivan le Terrible en sultan (fig. 23, p. 331, p. 350-351). Cette piste est très intéressante, car elle a probablement aidé à façonner ce concept du "despotisme asiatique» de la société russe qui devient un cliché à l'époque des Lumières. De son côté, Herberstein est le premier à affirmer que la Russie se situe en Asie et non en Europe (p. 290).

De la même façon, le thème du pouvoir absolu du tsar et de la servilité des Russes, qui a déjà fait couler beaucoup d'encre, ne peut être véritablement compris qu'en comparaison avec le "most Princelike, and gracious government " d'Élisabeth d'Angleterre qui se targue, selon Fletcher, d'être " Prince of subiectes, not of slaves » (p. 199, 215, 277-278). D'autres auteurs ont en tête les privilèges de la noblesse et des villes dans l'Empire germanique (p. 273-275) ou en Pologne-Lituanie (p. 270). Tous aboutissent à une question que les politologues se posent encore, à propos des aptitudes démocratiques de la Russie post-soviétique : est-ce le régime qui rend la population servile, ou bien est-il le produit de la servilité naturelle des Russes? Fletcher opte pour la première hypothèse (p. 282), tandis qu'Herberstein hésite, mais semble privilégier la seconde : gens illa magis servitute, quam libertate gaudet (p. 273, 296). 
Les illustrations et les cartes représentent un volet supplémentaire de la vaste enquête de Stéphane Mund. On a plaisir à feuilleter ses bonnes reproductions des gravures du xvie siècle, précisément référencées. Les remarques que l'on glane sur la course à la publication d'une première carte de la Russie (p.241-243, 254-258) et sur le souci d'Herberstein d'obtenir des représentations fiables des aurochs ou d'autres bêtes qu'il a observées en chemin sont aussi instructives et renforcent l'idée d'un tableau "globalement exact» du pays. L'auteur devrait toutefois insister sur l'extrême nouveauté de ces images. La cartographie n'existait alors quasiment pas en Russie (où l'on dressait des plans à main levée), tandis que le portrait y était encore dans les limbes. Celui de Vasilij III (reproduit p. 272), gravé par A. Hirsfogel vers 1549, sur les instructions d'Herberstein, est donc une pièce unique, malgré son caractère assez conventionnel. Le premier tsar de Russie, Ivan le Terrible, avait, certes, un pouvoir absolu, mais il ne pouvait embrasser son pays d'un seul coup d'œil comme était à même de le faire, en Occident, n'importe quel lecteur des Rerum Moscoviticarum Commentarii...

\section{NOTES}

1. Foreign descriptions of Muscovy: an analytic bibliography of primary and secondary sources, Columbus, Slavica Publishers, 1995; A people born to slavery: Russia in early modern European ethnography, 1476-1748, Ithaca-Londres, Cornell University Press, 2000 (Studies of the Harriman Institute). 